\section{Ultrasonic decontamination in smoked salmon experimentally contaminated with Listeria monocytogenes: Preliminary results}

\author{
Luca Pennisi, ${ }^{1}$ Daniele Di Clerico, ${ }^{2}$ \\ Luigi Costantini, ${ }^{1}$ Anna Rita Festino, ${ }^{1}$ \\ Alberto Vergara ${ }^{1}$ \\ ${ }^{1}$ Faculty of Veterinary Medicine, \\ University of Teramo; ${ }^{2}$ Next Cooking \\ Generation Srl, Milan, Italy
}

\begin{abstract}
The purpose of this work was to evaluate the effects of ultrasound (sonication) and their combination with temperature (thermosonication) on the inactivation of Listeria monocytogenes (LM) in smoked salmon. The trial was conducted on smoked salmon samples experimentally contaminated with a cocktail of 4 strains of Listeria monocytogenes (LM ATCC 19114, LM ATCC 15313, LM ATCC 19111 and LM ATCC 7644) at a final concentration of 8 $\log \mathrm{cfu} / \mathrm{g}$ and kept at $4^{\circ} \mathrm{C}$ until its use. Thermosonication treatments between $40^{\circ} \mathrm{C}$ and $50^{\circ} \mathrm{C}$ for 5,10 and 15 minutes proved to be more effective without altering the sensory characteristics of the food.
\end{abstract}

\section{Introduction}

The Genus Listeria is found naturally in agricultural environments such as soil, manure and water (Jeyaletchumi et al., 2012). The scientific literature frequently discusses the ability of these microorganisms to survive in the environment and in the equipment used to produce food as well as in domestic refrigerators (Azizoglu et al., 2014; Vergara et al., 2014).

Listeria monocytogenes is a pathogenic bacterium that can cause a rare but dangerous infection called listeriosis. The severity of listeriosis can range from mild gastroenteritis to severe illness (septicaemia, encephalitis, meningitis, abortion, etc.) and can lead to a high mortality rate in immunodeficient subjects (Swaminathan and Gerner-Smidt, 2007). In fact, some people have a higher risk of developing listeriosis, in particular the elderly ( $>65$ years), newborns and infants ( $<5$ years), and about $17 \%$ of cases of listeriosis affect pregnant women (Buzby, 2001; Okutani et al., 2004; Swaminathan and Gerner-Smidt, 2007; Dilber et al., 2009; Smith et al., 2009;
Gillespie et al., 2010; CDC, 2015).

According to the Food and Drug Administration (FDA), around 2,500 people suffer from listeriosis in the United States each year (FDA, 2011). The mortality rate could be between $20 \%$ and $30 \%$ of those who contract listeriosis (Swaminathan and Gerner-Smidt, 2007). Listeria monocytogenes is responsible for $19 \%$ of total deaths due to the consumption of contaminated food in the United States (Scallan et al., 2011).

According to a recent opinion of the European Food Safety Authority (EFSA), in Europe the cases of listeriosis have increased in particular between two groups of the population: individuals over 75 years of age and women between 25 and 44 years (likely due to pregnancy). The opinion covers the period 2008-2015 (EFSA, 2018).

The microorganism is commonly isolated from meat and meat products, fishery products, milk by-products and ready-to-eat foods (RTE), stored at refrigeration temperatures.

Conventional heat treatments (pasteurization or sterilization) are the techniques more frequently used for microbial decontamination of food products.

However, the demand for new technologies that are effective and have minimal impact on nutritional and sensory characteristics is constantly growing. Possibly, these technologies should be environmentally friendly, with a lower consumption of energy and therefore cheaper than conventional processes.

Among the alternative technologies for microbial inactivation, the scientific literature proposed pulsed electric fields, microfiltration, high hydrostatic pressures, and ultrasounds.

In recent years, ultrasounds have been shown to have a wide variety of applications, e.g. to increase meat tenderness or decontaminate foods. Sonication creates longitudinal waves that originate zones of alternate compression and expansion. (Sala et al., 1995). These zones of pressure change cause the so-called "cavitation" that generates gas bubbles in the product. These bubbles have a larger surface area during the expansion cycle, which increases gas diffusion, causing the bubble to expand. A point is reached at which the supplied ultrasonic energy is not sufficient to maintain the vapour phase in the bubble, thus generating a rapid condensation. The condensed molecules collide violently and create shock waves. These shock waves form regions of very high temperature and pressure, reaching up to $5500^{\circ} \mathrm{C}$ and $50,000 \mathrm{kPa}$ (Piyasena et al., 2003). The pressure variations resulting from these implosions are
Correspondence: Luca Pennisi, Faculty of Veterinary Medicine, University of Teramo, Località Piano d'Accio, 64100 Teramo, Italy. Tel. +39.0861 .166886$

E-mail:1mpennisi@unite.it

Key words: Sonication, thermosonication, Listeria monocytogenes, decontamination.

Contributions: The authors contributed equally.

Conflict of interests: The authors declare no potential conflict of interests.

Funding: None.

Availability of data and materials: The data that support the findings of this study are available from the corresponding author upon reasonable request.

Ethics approval and consent to participate: This research was conducted in accordance with all relevant guidelines and procedures.

Consent for publication: The manuscript does not contain any individual person's data in any form.

Received for publication: 15 July 2019.

Revision received: 10 December 2019.

Accepted for publication: 11 December 2019

This work is licensed under a Creative Commons Attribution-NonCommercial 4.0 International License (CC BY-NC 4.0).

CCopyright: the Author(s), 2020

Licensee PAGEPress, Italy

Italian Journal of Food Safety 2020; 9:8398

doi:10.4081/ijfs.2020.8398

the main bactericidal effect in ultrasounds. Hot spots can kill some bacteria, but they are very localized and do not affect a large enough area. The effectiveness of ultrasound depends on several factors, such as the type of bacterium treated, the product characteristics, the wave amplitude, the exposure/contact time and the treatment temperature. Several authors pointed out that the effectiveness can be greater if other decontamination technologies are associated with ultrasounds such as heat, low $\mathrm{pH}$, chlorination, etc. In fact, in combination with heat, ultrasound could accelerate the rate of food decontamination, thus reducing the duration and intensity of the heat treatment and the consequent damage (Zencher et al., 2001). In particular, the following treatment combinations have been studied: ultrasounds and high-pressure treatments (manosonication), heat treatments (thermosonication), and the combination of the three technologies (manothermosonication) 
(Baumann et al., 2005; Manas et al., 2000; Raso et al., 1998; Sala et al., 1995).

For the purposes of this work, only sonication and thermosonication treatments have been considered. Room temperature sonication treatments on Listeria monocytogenes do not have a powerful effect; in fact, the decimal reduction time is 4.3 minutes (Pagan et al., 1999). The combination of heat and high-power ultrasound was first explored by Ordonez et al. (1987). Thermosonication combines moderate heat $\left(37^{\circ} \mathrm{C}\right.$ to $\left.75^{\circ} \mathrm{C}\right)$ with ultrasound treatment. According to some authors, this treatment, compared to sonication alone, has a real effectiveness if the temperature is above $50^{\circ} \mathrm{C}$ (Lopez-Malo et al., 1999; Piyasena et al., 2003; Knorr et al., 2004; Dubrovic et al., 2011; Herceg et al., 2012). Wrigley and Llorca (1992) reported that a treatment at $40^{\circ} \mathrm{C}$ for 30 minutes can reduce Salmonella Typhimurium by $3 \mathrm{log} / \mathrm{cfu}$. Instead, Scouten and Beuchat (2002) reported that a treatment at $55^{\circ} \mathrm{C}$ for 5 minutes can reduce Salmonella enterica in alpha-alpha seeds by 3.62 $\log / \mathrm{cfu}$. Thermosonication was applied effectively to reduce the count of L. monocytogenes in cell suspension (Ugarte-Romero et al., 2007). Baumann et al. (2005) observed that after 5 minutes of treatment with thermosonication at $60^{\circ} \mathrm{C}$ in apple cider Listeria monocytogenes ATCC 10403S was inactivated during a 6-hour storage period at room temperature. The aim of the present work was to investigate the time-treatment parameters in smoked salmon samples experimentally contaminated with $L$. monocytogenes and immediately subjected to sonication and thermosonication at different time-temperature combinations.

\section{Materials and Methods}

120 samples of salmon, in packs of 200 g., produced by the same manufacturer, were purchased at a local supermarket on the day of the trial and kept in refrigerated conditions $\left(4^{\circ} \mathrm{C}\right)$ for $1 \mathrm{~h}$ until the time of treatment.

\section{Bacterial strains and preparation of the cocktail}

The bacterial strains used were four; Listeria monocytogenes ATCC 19114, Listeria monocytogenes ATCC 15313, Listeria monocytogenes ATCC 19111 and Listeria monocytogenes ATCC 7644.

The individual microorganisms were rehydrated in $9 \mathrm{~mL}$ of Buffered Peptone Water (BPW, Oxoid), and after 20 minutes the cultures were streaked on Tryptic Soy Agar (TSA, Oxoid) and incubated at $35^{\circ} \mathrm{C}$ for $22 \mathrm{~h}$. A colony was taken from each TSA plate, diluted in $10 \mathrm{~mL}$ of Tryptic Soy Broth
(TSB, Oxoid) and incubated at $35^{\circ} \mathrm{C}$ for 22 h. Cells were collected by centrifugation at $4000 \mathrm{rpm}$ for 20 minutes at $4^{\circ} \mathrm{C}$ and washed three times with BPW. The individual bacterial strains were resuspended in BPW to obtain a final concentration of about 108 $\mathrm{cfu} / \mathrm{mL}$. The final concentration of the inoculum was determined by a spectrophotometer at a wavelength of $550 \mathrm{~nm}$. The bacterial cocktail was prepared by mixing equal volumes of each ATCC strain and was tested before use by the pour plate technique according to ISO 11290-2 standard method. The smoked salmon was weighed, maintaining sterile conditions, to give samples of $25 \mathrm{~g}$. A spot inoculation method was then used to inoculate L. monocytogenes on smoked salmon samples (Mahmoud, 2010). Subsequently, the samples have been packaged under vacuum and subjected to sonication and thermosonication treatments within $10 \mathrm{~min}$ from inoculation.

\section{Sonication and thermosonication treatments}

Waveco ${ }^{\circledR}$, an ultrasonic bath with a capacity of 30 litres (Next Cooking Generation, Milano, Italy) was used for all ultrasound treatments. All samples were processed at $20 \mathrm{kHz}$ with $100 \%$ amplitude with focused ultrasonic wave according to the patent (International Application No.: $\mathrm{PCT} / \mathrm{IB} 2017 / 053465)$ at $20^{\circ} \mathrm{C}, 25^{\circ} \mathrm{C}, 30^{\circ} \mathrm{C}$, $40^{\circ} \mathrm{C}$ and $50^{\circ} \mathrm{C}$ for 5,10 and 15 minutes. Before and after each ultrasound treatment, all equipment was sanitized. During each trial, samples were taken before (in triplicate) and after treatment (in quintuplicate) to assess the initial contamination and the effectiveness of the decontamination treatment.

\section{Bacterial enumeration}

All samples were analysed according to the ISO 11290-2 standard method.

$25 \mathrm{~g}$ of untreated (control) and treated salmon at different times and temperatures were transferred to a sterile stomacher bag (Gosselin SM2B-01, Villeurbanne, France) containing $225 \mathrm{~mL}$ of Maximum Recovery Diluent (MRD, Oxoid), homogenized in a stomacher (BagMixer, Interscience) at room temperature for $1 \mathrm{~min}$. $1 \mathrm{~mL}$ of the homogenized sample was then diluted 10 times in series in $9 \mathrm{~mL}$ of sterile MRD and the appropriate dilutions were streaked onto appropriate selective media.

\section{Statistical analysis}

The effects of temperature and time were analysed through a one-way ANOVA. The level of significance was set at $\mathrm{P}<0.05$. The data was analysed using the software Excel 2010 (Microsoft Corporation).

\section{Results and Discussion}

Survival and reduction of L. monocytogenes cocktail in smoked salmon at five temperatures are shown in Table 1 and in Figure 1.

Table 1. Inactivation of Listeria monocytogenes cocktail after ultrasonic treatments in smoked salmon.

\begin{tabular}{llllll} 
Time & $20^{\circ} \mathrm{C}$ & $25^{\circ} \mathrm{C}$ & $30^{\circ} \mathrm{C}$ & $40^{\circ} \mathrm{C}$ & $50^{\circ} \mathrm{C}$ \\
5 & 0.58 & 0.72 & 1.24 & 1.91 & 2.44 \\
10 & 0.88 & 1.00 & 1.39 & 2.05 & 1.90 \\
\hline 15 & 0.97 & 1.08 & 2.02 & 2.14 & 2.12 \\
\hline
\end{tabular}

*Average values expressed in $\log \mathrm{cfu} / \mathrm{ml}$.

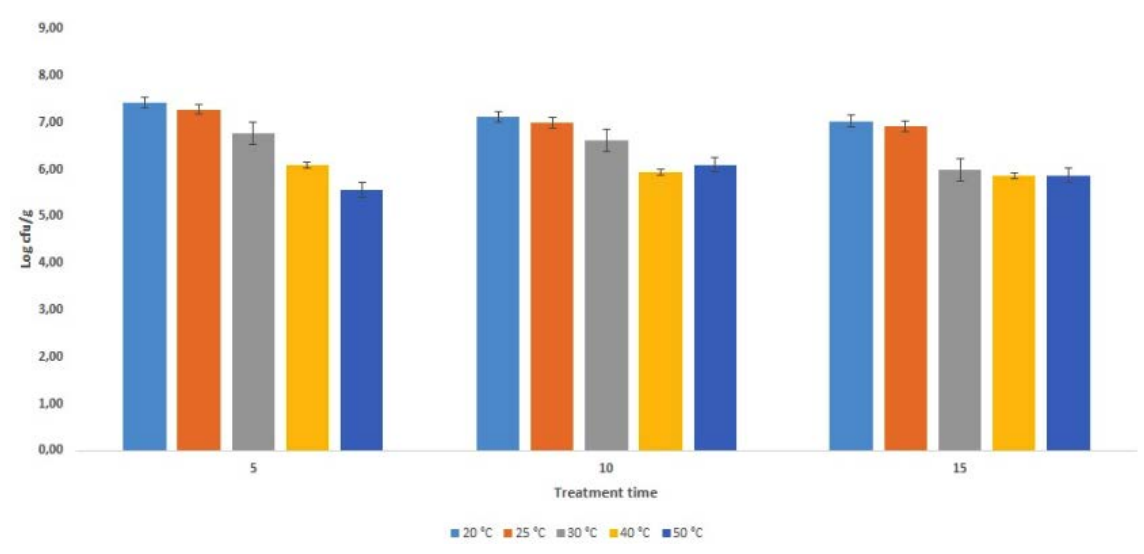

Figure 1. Survival of Listeria monocytogenes cocktail after ultrasonic treatments in smoked salmon. 
Inactivation at low temperatures $\left(20^{\circ} \mathrm{C}\right.$, $25^{\circ} \mathrm{C}$ ) was much less evident, if not negligible, compared to the other temperatures $\left(30^{\circ} \mathrm{C}, 40^{\circ} \mathrm{C}\right.$ and $\left.50^{\circ} \mathrm{C}\right)$.

The ultrasonic inactivation was 2.02 , 2.12 and $2.44 \log \mathrm{cfu} / \mathrm{gr}$ at $30^{\circ} \mathrm{C}$ for $15 \mathrm{~min}$ utes, at $40^{\circ} \mathrm{C}$ for 15 minutes, and at $50^{\circ} \mathrm{C}$ for 5 minutes, respectively.

However, no statistically significant difference was observed between the samples during the study.

The results obtained from this work are in accordance with other authors' results obtained in other foods. Baumann et al., (2005) obtained a similar reduction in apple cider treated at $50^{\circ} \mathrm{C}, 55^{\circ} \mathrm{C}$ and $60^{\circ} \mathrm{C}$. Earnshaw et al. (1995) reported a similar inactivation increase in whole milk, following the application of ultrasounds at high temperatures.

It is not clear why the treatment at $50^{\circ} \mathrm{C}$ for 10 minutes has given worse inactivation values than the other times and compared to the treatment at $40^{\circ} \mathrm{C}$ for the same time.

An explanation of this phenomenon has been described by Mason (1999), who hypothesized that, at certain temperatures, there might be an increase in the vapour pressure that suppresses, through a damping effect, the energy released when a cavitating bubble implodes thus lowering the rate of inactivation. Similar phenomena have already been observed and underlined by Pagan et al. (1999) during a $40^{\circ} \mathrm{C}$ manosonication treatments and Baumann et al. (2005) during thermosonication treatments at $60^{\circ} \mathrm{C}$.

\section{Conclusions}

The results of this study indicate that ultrasound treatments can improve the inactivation of Listeria monocytogenes at sublethal temperatures, maintaining the sensory characteristics of the treated samples. In fact, the smell has not undergone changes in any of the samples; instead, the colour has gradually decreased in intensity at higher temperatures, however, when the vacuum packs were opened, it immediately resumed tone. Therefore, this treatment regime could provide a solution for the smoked salmon industry, to achieve the food safety regulatory requirements. Our preliminary data can offer a basis to further investigate the effects of sonication or thermosonication in smoked salmon inoculated with L. monocytogenes.

The next steps will be the evaluation of shelf life and the effect on the pathogenic bacteria present in the samples, in particular the evolution of cell damage and repair phenomena.

\section{References}

Azizoglu RA, Gorski L, Kathariou S, 2014. Listeria and produce: A troublesome liaison! Available online: https://www.newfoodmagazine.com/art icle/15048/listeria-produce-troublesome-liaison

Baumann AR, Martin SE, Feng H, 2005. Power Ultrasound Treatment of Listeria monocytogenes in Apple Cider. J Food Protect 68:2333-40.

Beuchat LR, Farber JM, Garrett EH, Harris LJ, Parish ME, Suslow TV, 2001. Standardization of a method to determine the efficacy of sanitizers in inactivating human pathogenic microorganisms on raw fruits and vegetables. $\mathrm{J}$ Food Protect 64:1079-84.

Buzby JC, 2001. Children and Microbial Foodborne Illness. Food Rev 24:32-7.

Centers for Disease Control and Prevention (CDC), 2015. Multistate outbreak of listeriosis linked to commercially produced, prepackaged caramel apples. Available online: http://www.cdc.gov/listeria/outbreaks/c aramel-apples-12 - 14/index.html

Dilber E, Aksoy A, Çakir M, Bahat E, Kamasak T, Dilber B, 2009. Listeria monocytogenes meningitis in two immunocompetent children. Ann Trop Paediatr 29:225-9.

Dubrović I, Herceg Z, Jambrak AR, Badanjak M, Dragović-Uzelac V, 2011. Effect of high intensity ultrasound and pasteurization on anthocyanin content in strawberry juice. Food Technol Biotechnol 49:196-204.

Earnshaw RG, Appleyard J, Hurst RM, 1995. Understanding physical inactivation processes: combined preservation opportunities using heat, ultrasound and pressure. Int J Food Microbiol 28:197219.

European Food Safety Authority (EFSA), 2018. Listeria monocytogenes contamination of ready-to-eat foods and the risk for human health in the EU. EFSA J 16:5134-311.

Food and Drugs Administration (FDA), 2011. Food Safety for Pregnant Women. Available online: http://www.fda.gov/food/foodborneillnesscontaminants/peopleatrisk/ucm 312 704.htm

Gillespie IA, Mook P, Little CL, Grant K, Adak GK, 2010. Listeria monocytogenes infection in the over-60s in England between 2005 and 2008: a retrospective case-control study utilizing market research panel data. Foodborne Pathog Dis 7:1373-9.

Herceg Z, Jambrak AR, Lelas V, Thagard
SM, 2012. The Effect of high intensity ultrasound treatment on the amount of Staphylococcus aureus and Escherichia coli in milk. Food Technol Biotechnol 50:46-52.

Jeyaletchumi P, Tunung R, Selina PM, Chai LC, Radu S, Farinazleen MG, Cheah YK, Mitsuaki N, Yoshitsugu N, Kumar MP, 2012. Assessment of Listeria monocytogenes in salad vegetables through kitchen simulation study. J Trop Agric Food Sci 40:55-62.

Knorr D, Zenker M, Heinz V, Lee DU, 2004. Applications and potential of ultrasonics in food processing. Trends Food Sci Technol 15:261-6.

Lopez-Malo A, Palou E, JimenezFernandez M, Al-Zamora SM, Guerrero S, 2005. Multifactorial fungal inactivation combining thermosonication and antimicrobials. J Food Eng 67:87-93.

Mahmoud BSM, 2010. Effects of X-ray irradiation on Escherichia coli O157:H7, Listeria monocytogenes, Salmonella enterica and Shigella flexneri inoculated on shredded iceberg lettuce. Food Microbiol 27:109-14.

Manas P, Pagan R, Raso J, Sala FJ, Condon $\mathrm{S}, 2000$. Inactivation of Salmonella Typhimurium, and Salmonella Senftenberg by ultrasonic waves under pressure. J Food Protect 63:451-6.

Mason TJ, 1999. Sonochemistry. Oxford Science Publications. Oxford, England.

Okutani A, Okada Y, Yamamoto S, Igimi S, 2004. Nationwide survey of human Listeria monocytogenes infection in Japan. Epidemiol Infect 132:769-72.

Ordoñez JA, Aguilera MA, Garcia ML, Sanz B, 1987. Effect of combined ultrasonic and heat treatment (thermoultrasonication) on the survival of a strain of Staphylococcus aureus. J Dairy Res 54:61-7.

Pagan R, Manas P, Raso J, Condon S, 1999. Bacterial resistance to ultrasonic waves under pressure at non-lethal (manosonication) and lethal (manothermosonication) temperatures. Appl Environ Microbiol 65:297-300.

Pagan R, Manas P, Alvarez I, Condon S, 1999. Resistance of Listeria monocytogenes to ultrasonic waves under pressure at sublethal (manosonication) and lethal (manothermosonication) temperatures. Food Microbiol 16:139-48.

Piyasena P, Mohareb E, McKellar RC, 2003. Inactivation of microbes using ultrasound: a review. Int $\mathrm{J}$ Food Microbiol 87:207-16.

Raso J, Palo A, Pagan R, Condon S, 1998. Inactivation of Bacillus subtilis spores by combining ultrasonic waves under pressure and mild heat treatment. J Appl 
Microbiol 85:849-54.

Sala FJ, Burgos J, Condon S, Lopez P, Raso J, 1995. Effect of heat and ultrasound on micro-organisms and enzymes. In: Gould, GW. (ed) New Methods of Food Preservation. London, Blackie Academic and Professional, pp. 176204.

Scallan E, Hoekstra RM, Angulo FJ, Tauxe RV, Widdowson MA, Roy SL, Jones JL, Griffin PM, 2011. Foodborne illness acquired in the United States-Major pathogens. Emerg Infect Dis 17:7-15.

Scouten AJ, Beuchat LR, 2002. Combined effects of chemical, heat and ultrasound treatments to kill Salmonella and Escherichia coli $\mathrm{O} 157: \mathrm{H} 7$ on alfalfa seeds. J Appl Microbiol 92:668-74.

Smith B, Kemp M, Ethelberg S, Schiellerup P, Bruun BG, Gerner-Smidt P, Christensen JJ, 2009. Listeria monocytogenes: Maternal-foetal infections in Denmark 1994-2005. Scand J Infect Dis 41:21-5.

Swaminathan B, Gerner-Smidt P, 2007. The epidemiology of human listeriosis. Microb Infect 9:1236-43.

Ugarte-Romero E, Feng H, Martin SE, 2007. Inactivation of Shigella boydii 18 IDPH and Listeria monocytogenes Scott A with power ultrasound at different acoustic energy densities and temperatures. J Food Sci 72:103-7.

Vergara A, Festino AR, Di Ciccio P,
Costanzo C, Pennisi L, Ianieri A, 2014. The management of the domestic refrigeration: microbiological status and temperature. Br Food J 116:1047-57.

Wrigley DM, Llorca NG, 1992. Decrease of Salmonella typhimurium in skim milk and egg by heat and ultrasonic wave treatment. J Food Protect 55:678- 80.

Zencher M, Heinz V, Knorr D, 2001. Combined application of ultrasound and temperature for energy-saving and mild preservation of liquid food. Proceedings of the Third European Congress of Chemical Engineering. Nuremberg, Germany. 2001; June 26-28. 